\title{
Médiévales
}

Langues, Textes, Histoire

69 | automne 2015

Travailler à Paris (XIIIe-XVIe siècle)

\section{Alexis WILKIN et Jean-Louis KUPPER (dir.), Évêque et prince. Notger et la Basse-Lotharingie aux alentours de l'an Mil}

Liège, Presses Universitaires de Liège, 2013, 606 p.

\section{Tristan Martine}

\section{(2) OpenEdition}

\section{Journals}

Édition électronique

URL : https://journals.openedition.org/medievales/7657

DOI : 10.4000/medievales.7657

ISSN : 1777-5892

Éditeur

Presses universitaires de Vincennes

Édition imprimée

Date de publication : 30 novembre 2015

Pagination : 206-208

ISBN : 978-2-84292-444-7

ISSN : 0751-2708

Référence électronique

Tristan Martine, «Alexis wiLkin et Jean-Louis kUPPER (dir.). Évêque et prince. Notger et la Basse-Lotharingie aux alentours de l'an Mil », Médiévales [En ligne], 69 | automne 2015, mis en ligne le 12 décembre 2015, consulté le 24 avril 2022. URL : http://journals.openedition.org/medievales/7657 ; DOI : https:// doi.org/10.4000/medievales.7657

Ce document a été généré automatiquement le 24 avril 2022

Tous droits réservés 


\section{Alexis WILKIN et Jean-Louis KUPPER (dir.), Évêque et prince. Notger et la Basse-Lotharingie aux alentours de l'an Mil}

Liège, Presses Universitaires de Liège, 2013, 606 p.

Tristan Martine

\section{RÉFÉRENCE}

Alexis WILKIN et Jean-Louis KUPPER (dir.), Évêque et prince. Notger et la Basse-Lotharingie aux alentours de l'an Mil, Liège, Presses Universitaires de Liège, 2013, 606 p.

1 Ce livre est issu d'un colloque qui s'est tenu en 2008 à l'Université de Liège à l'occasion du millénaire de la mort de Notger, fondateur de la principauté épiscopale de Liège et source d'inspiration intarissable pour l'historiographie belge, comme l'explique dès l'introduction Jean-Louis Kupper. En 1905, Godefroid Kurth publiait son Notger de Liège et la civilisation au $X^{e}$ siècle, qui fait encore référence aujourd'hui. Depuis, de nombreux articles, un ouvrage (Notger et Liège : l'an mil au cœur de l'Europe ${ }^{1}$ ) et une exposition (Liège autour de l'an mil, la naissance d'une principauté2) furent consacrés à ce personnage. Pour autant, que l'on ne s'y trompe pas, il ne s'agit pas ici d'une nouvelle analyse détaillée de sa vie et de son œuvre, mais bien d'une synthèse beaucoup plus large sur la BasseLotharingie autour de l'an mil (même si la plupart des communications ne traitent en réalité que du sud de la Basse-Lotharingie, laissant de côté l'actuel territoire hollandais).

2 La première partie porte sur l'essor économique du pays mosan. Deux articles sont consacrés à la Meuse : Marc Suttor étudie tout d'abord le rôle économique important de cette artère essentielle du commerce, puis Dietrich Lohrmann dresse une typologie des ressources et des aménagements hydrauliques dans ce même bassin. Malgré la 
difficulté à saisir le détail du temporel de la cathédrale, Olivier Bruand montre ensuite que Notger a su développer les revenus du patrimoine liégeois par le biais d'une organisation réticulaire, en renforçant les différents pôles locaux, situés le long des routes et des cours d'eau. Cette polarisation stratégique sur les castra de la Meuse et les différents nœuds routiers passe par un renforcement de l'emprise régionale, en se concentrant manifestement sur des terres et des droits géographiquement proches. Cette hiérarchisation précoce de l'espace en réseau, mise également en évidence par l'étude des privilèges économiques, passe aussi par un certain nombre de places secondaires qui servent souvent de relais routiers. Arnoud-Jan Bijstervel s'intéresse à des thématiques similaires, mais uniquement en Texandrie et pour une période bien plus longue ( $\mathrm{x}^{\mathrm{e}}$-XII ${ }^{\mathrm{e}}$ siècle). Il montre que la formation du patrimoine liégeois, le long de la Meuse, en partie au-delà des frontières diocésaines liégeoises, a renforcé le pouvoir ecclésiastique de l'évêque. Les biens et droits fonciers, situés sur les routes menant de la Basse Meuse vers Liège ont été acquis, notamment via l'avouerie, pour leur valeur économique mais aussi, et surtout, pour leur valeur stratégique - les évêques de Liège tentant d'exercer le pouvoir public au-delà des territoires qui leur étaient échus en vertu des titres comtaux. Enfin, deux communications reviennent sur la question des corvées dans le pays mosan : Jean-Pierre Devroey examine dans le détail des extraits de trois polyptyques différents, tandis qu'Alexis Wilkin analyse les structures du travail et de la grande propriété en Hesbaye liégeoise à partir de l'exemple des domaines de l'abbaye de Saint-Trond.

3 La deuxième partie est consacrée au contexte politique. Analysant différents épisodes de faide, notamment la célèbre "vengeance d'Adèle ", Régine Le Jan démontre que la vengeance est le mode d'expression normal et légitime des luttes politiques. La haine est un ressort politique majeur, faisant passer au second plan le souci de la charité qu'impose l'idéologie chrétienne, ce qui serait plus marqué en Lotharingie qu'ailleurs, l'instabilité politique chronique y empêchant une médiation suffisante pour contenir une compétition extrêmement agressive. La situation liégeoise est ensuite comparée, de manière éclairante, avec celle des évêques de Cambrai (Charles Mériaux) et d'Utrecht (Rolf Grosse), les deux communications interrogeant la figure de l'évêque ottonien membre d'une Église impériale en réalité bien plus diverse et complexe que ce qui a longtemps été avancé par une historiographie sous l'emprise de l'idéal de l'État moderne. Yves Sassier livre une analyse très poussée des tractations diplomatiques de l'année 985 à partir des lettres de Gerbert d'Aurillac, tandis qu'Alain Dierkens examine différents aspects de la querelle entre Folcuin et Rathier au sujet de l'abbaye de Lobbes, réglée par Notger. Enfin, Michel Margue revient sur les stratégies des grands aristocrates laïques, qui prirent bien souvent modèle sur les politiques épiscopales dans les cités et montre qu'évêques et comtes ne doivent pas être opposés de manière caricaturale : tous deux ont tenté d'ancrer progressivement leur pouvoir, de fonder des ébauches de "principautés territoriales", à l'aide notamment d'une politique de fortification, très bien analysée ici, en alternant recherche de leur intérêt propre et soutien au pouvoir central, ce qui, bien souvent, n'était pas contradictoire.

4 La troisième partie, culturelle, comprend tout d'abord trois approches urbanistiques: François Heber-Suffrin et Anne Wagner montrent que différentes cités épiscopales présentent un véritable " urbanisme symbolique ", reflétant les exigences idéologiques de leurs évêques ; Christian Sapin dresse un parallèle avec les évêques constructeurs en Bourgogne et Ludwig Falkenstein revient sur les rapports entre Notger et Aix-laChapelle. Suivent trois réflexions sur des aspects « religieux »: Florence Close analyse 
la propagation de modèles liturgiques dans le diocèse de Liège au $\mathrm{x}^{\mathrm{e}}$ siècle, Pierre Riché revient sur les relations entre Notger et l'évêque Gerbert d'Aurillac, devenu le pape Sylvestre II, tandis que Fabrizio Crivello s'intéresse à l'enluminure liégeoise. Enfin, Julien Maquet s'intéresse aux aspects juridiques et judiciaires de l'épiscopat de Notger.

La quatrième partie regroupe des articles concernant les écrits de ou sur Notger. Clemens M. M. Bayer prouve que la Vita Hadelini est bien l'œuvre de Notger, Jeffrey R. Webb examine ses commandes hagiographiques et historiographiques, et Nicolas Mazeure montre l'attention qu'il porta aux pratiques de la mise par écrit diplomatique et à l'exploitation des chartes, à partir de manuscrits de Stavelot-Malmedy. Enfin, Philippe Raxhon explique les raisons du consensus dans l'historiographie belge autour de la figure notgérienne, qui échappa notamment aux critiques des libéraux au XIX ${ }^{e}$ siècle.

6 L'ouvrage est doté d'illustrations de très belle qualité. Rejetées en fin de volume, elles sont malheureusement peu utilisables, car elles ne sont pas accompagnées d'un titre ou d'une notice explicative, ni même d'un renvoi à l'article qu'elles sont censées illustrer. Une remarque de fond ensuite: cet ouvrage veut se distinguer des traditionnelles éditions d'actes en présentant une plus grande cohérence, ambition clairement affichée dès l'introduction. Néanmoins les différentes parties thématiques se révèlent très larges et accueillent donc des articles extrêmement divers (la partie « culturelle » voit ainsi se côtoyer un article sur l'urbanisme, un autre sur l'office de la Trinité et un dernier sur des questions juridiques). Ces différences, pour ne pas dire ces divergences, se retrouvent également dans les illustrations, et l'on remarquera ainsi que les deux seules cartes de la Basse-Lotharingie (illustrant les communications de Charles Mériaux et de Michel Margue) présentent des frontières très différentes (il faut néanmoins reconnaître que la question des frontières lotharingiennes reste, aujourd'hui encore, très épineuse). Un regret enfin: l'absence de communications purement archéologiques, ce qui est d'autant plus regrettable qu'il existe de remarquables travaux portant sur cette période et cet espace (on pense notamment aux recherches de M. de Waha, P. Mignot, A. Matthys, F. Chantinne ou D. Callebaut). Mais cela s'explique peut-être par la volonté de ne pas revenir sur des sujets déjà abordés dans le cadre d'un récent colloque sur les résidences aristocratiques dans la Francia Media au $\mathrm{x}^{\mathrm{e}}$ siècle, dont les actes seront très prochainement publiés. Cette utile synthèse, aussi ambitieuse que monumentale, n'en reste pas moins un très bel ouvrage, et l'on ne peut qu'espérer qu'un tel travail voie rapidement le jour concernant l'autre moitié de l'ancien royaume de Lothaire II : la Haute-Lotharingie.

\section{NOTES}

1. J.-P. DelVille, J.-L. KuPPER, M. LAFFInEUR-CREPIN, Notger et Liège : l'an mil au cœur de l'Europe, Alleur, 2008.

2. J.-L. KUPPER, P. GEORGE éd., Liège. Autour de l'an mil, la naissance d'une principauté ( $X^{e}$-XII ${ }^{e}$ siècle), Liège, 2000. 